\title{
Animal models of transient ischemic attack: a review
}

\author{
Jiahui Wang ${ }^{1} \cdot$ Ping Zhang $^{1}$ (i) $\cdot$ Zhouping Tang $^{1}$ \\ Received: 30 November 2019 / Accepted: 30 January 2020 / Published online: 11 February 2020 \\ (c) The Author(s) 2020
}

\begin{abstract}
Transient ischemic attack (TIA) is defined as a brief episode of neurological dysfunction caused by focal cerebral ischemia. TIA is a critical early warning signal of stroke. Patients with TIA may have long-term cognitive decline. The pathogenesis and pathological changes of TIA have not been fully elucidated. Animal models can simulate the process of human diseases and are essential tools to investigate injury mechanisms and therapeutic approaches of TIA. Most TIA animal models are based on ischemic stroke models and the definition of TIA. Each model has unique strengths and weaknesses. The establishment of a successful and reliable TIA model should follow three criteria: (1) objective evidence of cerebral arteries occlusion and reperfusion, (2) no permanent neurological deficit, and (3) no acute cerebral infarction. However, experimental animal models are impossible to be completely consistent with human TIA, because TIA itself is a heterogeneous disease. In the present review, the selection of animals, methodological development, and evaluation of cerebral blood flow of animal models of TIA are comprehensively evaluated.
\end{abstract}

Keywords Transient ischemic attack $\cdot$ Animal model $\cdot$ Cerebral blood flow monitoring

\section{Introduction}

Transient ischemic attack (TIA) is a brief episode of neurological dysfunction caused by focal brain, spinal cord or retina ischemia, without acute cerebral infarction [1]. Because of the absence of residual neurological deficits and imaging-based evidence of cerebral infarction, TIA was previously considered a benign cerebral ischemic event. Nevertheless, recently, TIA has been found to be an important early warning signal of stroke. Up to $23 \%$ of patients with ischemic stroke have experienced TIA during the hours to days preceding the stroke [2]. Additionally, patients with TIA may exhibit long-term cognitive decline, which is a key risk factor for dementia $[3,4]$. Therefore, the prevention and

Ping Zhang

ppkitty0609@163.com

$\triangle$ Zhouping Tang

ddjtzp@163.com

Jiahui Wang

1371976645@qq.com

1 Department of Neurology, Tongji Hospital, Tongji Medical College, Huazhong University of Science and Technology, No. 1095 Jiefang Road, Wuhan 430030, China treatment of TIA should not be ignored. However, the actual diagnosis and treatment of TIA is not optimal. Studies indicate that the age-standardized incidence of TIA in Europe ranges from 28 to 59/100,000/year [5]. Another study reports that the age-standardized morbidity rate of TIA in China is $2.27 \%$, but the diagnostic rate and standardized treatment rate are only $16.0 \%$ and $4.07 \%$, respectively [6]. To improve the diagnosis and treatment strategy of TIA, it is necessary to develop an appropriate animal model that can simulate the characteristics of human TIA to enable the investigation of injury mechanisms, pathological changes and interventions for TIA. This review summarizes the selection of animals, methodological development and assessment of cerebral blood flow in animal models of TIA.

\section{Experimental TIA models}

\section{Selection of species}

TIA models may involve both small and large animals (e.g., mice, rats, guinea pigs, rabbits, pigs, monkeys, and baboons), and now most of the TIA modeling are performed in small animals such as mice and rats. There are some advantages of utilizing large animals to study TIA. The 
brains of large animals, especially non-human primates such as monkeys and baboons, are similar to the human brain in structure and function, which may enable the experimental results obtained from large animals to more effectively translate to clinical applications. However, large animal models are costly and involve ethical restrictions. It is also difficult to establish a stable TIA model in large animals due to collateral circulation and abundant vascular anastomosis [7].

Compared to large animals, the use of small animals presents distinct advantages, including an accessible supply, lower cost, less ethical restrictions, and most of all, the ease of replicability. The rat is one of the most commonly used animals in TIA studies due to the following advantages: (1) its similarities to humans in cerebrovascular structure [8], (2) the ability to use neurological and behavioral measurements to evaluate the severity of cerebral ischemic injury [9], (3) its moderate body size which facilitates the monitoring of physiologic parameters, and (4) its small brain size which allows for in vivo freezing techniques for metabolite studies [10]. In addition, since the mouse has an established genetic foundation and can be genetically homogeneous, it is widely used in transgenic technology studies to further explore the molecular pathology of TIA $[11,12]$. However, there are significant differences between small animals and humans in brain structure and function (e.g., size, gray matter distribution) [13], therefore, the pathological characteristics of small animal TIA models may differ greatly from human TIA.

In addition to animal species, the gender and age of animals can also affect the experimental results of TIA models. Since the estrogen has a neuroprotective effect which can alleviate cerebral ischemic injury [14, 15], male animals are used in most studies. Older animals exhibit pathological changes in the carotid artery, such as vascular tortuosity, hardening and lumen stenosis [16], which may confound a TIA model. Thus, older animals are typically not used.

Male adult rats are the most commonly used animals for the preparation of TIA models, but there is currently no unified standard for species selection. Due to the diversity of anatomical structures, functions and physiological characteristics of different species, established models differ in pathological mechanisms and disease manifestations. In practical applications, one should comprehensively consider the design, purpose, and funding of a study and try to choose economical and available animals with simple structures and similar characteristics to human diseases to achieve reliable results.

\section{Model selection}

TIA animal models are rare in the literature, most of which are based on ischemic stroke models and the definition of TIA. There is currently a lack of models specifically for establishing TIA. In this section, we would like to describe all the ischemic models available and present the possibility for their use in TIA modelling. Among the ischemic models, the middle cerebral artery occlusion (MCAO) is the most widely used method for inducing TIA, including craniotomy and intraluminal suture models. There are also photothrombosis, endothelin-1, embolic and platelet aggregation models (Table 1).

\section{MCAO model}

The middle cerebral artery (MCA) is the most frequently affected cerebral vessel in human ischemic cerebral vascular disease. Therefore, models that occlude this artery have the greatest translational potential.

\section{Proximal MCAO model}

The proximal MCAO model is also known as the intraluminal suture MCAO model, which is currently the most common method for TIA modeling. This method involves inserting a suture into the internal carotid artery (ICA) and advancing it until it blocks the origin of the MCA, causing a sharp decrease in the blood flow to the frontoparietal cortex and striatum. According to the path of the suture into the ICA, this model can be divided into two categories: the common carotid artery (CCA) approach and the external carotid artery (ECA) approach. The CCA approach is relatively simple to perform, but the reperfusion is achieved by the blood supply from contralateral cerebral circulation via the circle of Willis, which alters cerebral hemodynamics [17]. Therefore, the ECA approach is more consistent with clinical practice because it retains the anatomical integrity required for reperfusion.

The intraluminal suture MCAO model requires no craniotomy and is minimally invasive. Its greatest advantage is the ability to precisely control the duration of ischemia and efficiently initiate reperfusion by withdrawing the suture. However, the suture model has several disadvantages. First, it is difficult to confirm the success of this model without the help of cerebral blood flow (CBF) monitors. Second, the suture may interrupt the other branches of the ICA while occluding the MCA, resulting in additional ischemic injury. Third, the carotid intima may be damaged by the suture [18], which can cause thrombosis and affect histopathological results. Fourth, the cerebral vessels suddenly and completely recover recanalization after the suture is withdrawn, which is inconsistent with the hemodynamic characteristics of TIA patients. Additionally, this model shows no response to anticoagulant and antiplatelet therapy [19], and thus it is not an ideal model for studying the prevention and treatment measures of TIA. Finally, the reproducibility of this model is influenced by many factors, such as 


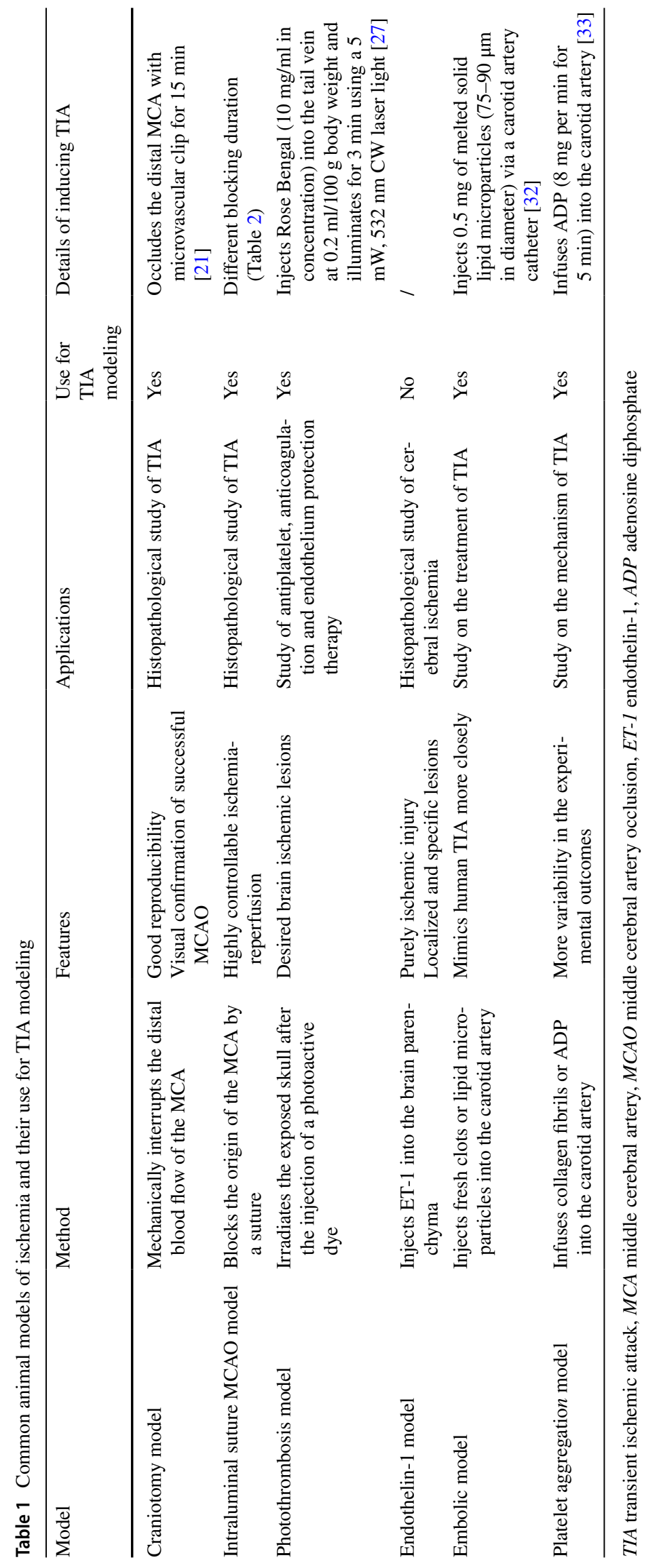


suture diameter and coating. The insertion length of suture also affects the degree of CBF decline, causing different ischemic injury. However, in recent years, with the application of CBF monitors in the modeling process, the consistency and success rate of this model have been greatly enhanced. CBF monitors not only help to avoid insufficient ischemia but also reduce the occurrence of complications (e.g., subarachnoid hemorrhage).

It is worth noting that the infarct thresholds (the minimum duration of ischemia that can cause cerebral infarction) vary in different animals used in the suture method of TIA. The mechanism for this variation is still unclear and may be caused by many factors, including differences in the composition of the circle of Willis, the distribution of gray and white matter, neuron density and other neuromorphological features [20]. Furthermore, because of individual differences in the formation of collateral circulation, the same strain may present different infarct thresholds. Additionally, the experimental results of the suture method vary greatly, and the filament, anesthesia and even the operation skill will affect the reproducibility of this model. In conclusion, the reasons for the different infarct thresholds among species need to be further explored. When this method is used in a TIA model, a pilot experiment should be conducted to clarify the infarct threshold of this animal (Table 2).

\section{Distal MCAO model}

The distal MCAO model is also referred as the craniotomy model. In this model, the MCA is exposed firstly via the temporal or orbital route. The distal blood flow of the MCA is then temporarily interrupted by microvascular clip [21], balloon or blunt micropipette compression [22, 23], microsurgical hook lift [24] or suture ligation [25], causing the cortical ischemic injury.

The greatest advantage of using this method to establish a TIA model is that the different mouse and rat strains currently studied (including spontaneously hypertensive rats [21], Swiss albino mice [22, 23] and Wistar rats [24]) have consistent infarct thresholds. Specifically, no cerebral infarction confirmed by MRI occurs when the MCA is occluded for less than $15 \mathrm{~min}$. Thus, when establishing a TIA model with this method, one can choose " $15 \mathrm{~min}$ " for a preliminary experiment to further explore the exact infarct threshold. Additionally, in this model, the MCA is blocked under direct microscope observation, and so it has high reliability, high success rate and good repeatability.

The disadvantages of this model mainly relate to invasive craniotomy, which involves the risk of intracranial infection, and may cause MCA or cortical tissue damage. Furthermore, the procedure requires skilled microsurgery techniques. These disadvantages limit the broad application of this method in TIA modeling to some extent.

\section{Modified photothrombosis model}

This model is based on the principle of intravascular photo-oxidation. A light-sensitive dye (e.g., Rose Bengal) is injected intravenously or intraperitoneally, and after irradiating the exposed skull with the light of a specific wavelength, oxygen radicals are generated, which induce vascular endothelium damage, platelet aggregation, and thrombosis [26], thereby resulting in cortical ischemic injury. This method is usually used to model ischemic stroke. However, Liu et al. [27] optimized the relevant parameters and developed a TIA rat model. They decreased the light intensity $(5 \mathrm{~mW})$ and reduced the illumination duration ( $3 \mathrm{~min}$ ), which caused unstable microthrombus formation in selected cortical vessels, with CBF dropping

Table 2 Infarct thresholds of several mouse and rat strains (suture method)

\begin{tabular}{|c|c|c|c|}
\hline Species, strain & $\begin{array}{l}\text { rCBF during } \\
\text { occlusion }(\%)\end{array}$ & Infarct threshold & $\begin{array}{l}\text { The duration of } \\
\text { MCAO for TIA model } \\
\text { (min) }\end{array}$ \\
\hline Rat, SD [18] & 20 & $\begin{array}{l}10 \text { min } \\
\text { Hippocampal infarcts were observed in } 33.3 \%(2 / 6) \text { of rats* }\end{array}$ & $<5$ \\
\hline Rat, Wistar [20] & 24 & $\begin{array}{l}12.5 \text { min } \\
\text { Caudate nucleus infarcts were observed in } 16.7 \%(1 / 6) \text { of rats* }\end{array}$ & $<10$ \\
\hline Mouse, NMRI [35] & 15 & $\begin{array}{l}12.5 \mathrm{~min} \\
\text { Cortical infarcts were observed in } 16.7 \%(1 / 6) \text { of mice* }\end{array}$ & $<10$ \\
\hline Mouse, ICR-CD1 [36] & 15 & $\begin{array}{l}10 \text { min } \\
\text { Striatal infarcts were observed in } 50.0 \% \text { of mice* }\end{array}$ & $<10$ \\
\hline Mouse, C57BL/6 [37] & 34 & No infarcts were found in any mice after MCAO for $5 \mathrm{~min} *$ & \\
\hline
\end{tabular}

$r C B F$ relative cerebral blood flow, which is the percentage of $\mathrm{CBF}$ in the basal CBF

*Infarcts that were confirmed by MRI; as shown in the table, 10 min can be selected for TIA-related study in the pre-experiment 
to $24 \%$ of the baseline level. Within 1 to $2 \mathrm{~h}$ post-ischemia, the thrombus began to dissolve spontaneously. At $4 \mathrm{~h}$ postischemia, reperfusion was observed, and the $\mathrm{CBF}$ returned to $88 \%$ of the baseline level, accompanied by the restoration of neurovascular function. The whole process was similar to clinical TIA. Unfortunately, TTC staining at $24 \mathrm{~h}$ showed that there were still tiny infarcts in the cortex, which might be associated with silent lacunar infarcts, so this model differs from the clinical definition of TIA, characterized by the absence of infarction.

In contrast to the MCAO model, the photothrombosis model can produce ischemic injury in specific brain regions. In addition, this model is minimally invasive and the survival rate is high. The size and depth of ischemic injury can be controlled by adjusting the dye concentration, light intensity and illumination duration. Furthermore, the process resembles human cerebral thrombosis, so this model can be used in the study of antiplatelet, anticoagulation and endothelium protection therapy. However, the photothrombosis model requires complex experimental equipment, and direct damage to brain tissue is a substantial risk, which may influence histopathology results. Another limitation of this model is that while the infarct volume of the modified method is significantly reduced compared to the traditional method, due to thrombosis and the inability to achieve controllable reperfusion, the occurrence of cerebral infarction cannot be avoided, which is inconsistent with the clinical definition of TIA. Therefore, this is not a recommended model of TIA.

\section{Endothelin-1 model}

Endothelin-1 (ET-1) is a potent and reversible vasoconstrictor peptide which can be used to induce cerebral ischemia models. Following stereotaxic intracerebral injection of ET-1, CBF is significantly decreased $(50 \%)$, then recovers to baseline levels over several hours [28]. Horie et al. [29] injected the same dose of ET-1 into the brain parenchyma of SD rats and four different mouse strains, inducing large and reproducible lesions in rats, with no lesions in mice. The reason for this difference may be the different expression of ET-1 receptor isoforms in mice and rats, resulting in different responses of rats and mice to ET-1. As we know, the mouse brain is rich in endothelin-B receptor which mediates vasodilation, leading to the poor ET-1-mediated cerebral vasoconstriction and an inability to induce cerebral infarction. This is consistent with the pathological characteristics of TIA. However, due to the absence of CBF monitoring in this study, it is not clear whether effective CBF decline occurred after ET-1 injection in the mice. Therefore, further investigation to determine whether the mouse ET-1 model can be used for TIA-related research is warranted, but at present, this model has only been applied to rats.

Compared with the MCAO model, the ET-1 model can induce focal ischemia in superficial or deep brain regions, with lesions that are more localized and specific. This model can also be optimized by adjusting the corresponding parameters, such as the dose and infusion mode of ET-1 to control the severity and duration of ischemia. Importantly, the pathological changes of this model are specifically caused by ischemic injury rather than inflammatory reactions [28], which may be more relevant to clinical TIA pathology. However, ET-1 generally causes severe cerebral ischemia (except in mice) due to its robust vasoconstrictive effects, and induces cerebral infarction. Therefore, strictly speaking, this model is not a specific TIA model.

\section{Embolic model}

The embolic model can be divided into two categories: thromboembolic and non-clot embolic models. In the thromboembolic model, a fresh clot is used for the establishment of a TIA model, as older clot is resistant to thrombolysis and cannot autolysis, which can cause extensive cerebral infarction. In the non-clot embolic model, a lipid microparticle is the most common embolus.

\section{Fresh clot model}

Microembolism is considered a major cause of TIA, and thus the thromboembolic model has strong face value. Culp et al. [30] directly injected fresh clots $(1.0 \mathrm{~mm}$ length, $0.6 \mathrm{~mm}$ diameter) into the ICA of rabbits. Angiography revealed that the injected clots flowed to the MCA in most rabbits, but $46 \%$ of cases presented incomplete MCA occlusion or no visible occlusion. TTC staining found that $60 \%$ of cases had no infarcts, possibly resulting from prompt autolysis of the clots and vascular recanalization, or adequate vasodilation or collateral development. This model mimics human TIA more closely than other models and is a valuable tool for studying TIA-related treatment.

Disadvantages of the thromboembolic model include: (1) the distribution of clots in cerebral vessels is indefinite, and the volume and location of lesions vary, (2) reperfusion is uncontrollable and the duration of ischemia cannot be reliably determined, (3) the rate of intracerebral hemorrhage and mortality are high.

\section{Lipid microparticle model}

The physicochemical properties of lipid microparticles are similar to those of lipid-rich emboli derived from atherosclerotic plaques, which are the major source of microembolism, and thus this model also simulates clinical TIA. 
Based on its characteristics of homogenous sphere appearance and rapid and consistent dissolvability [31], Tsai et al. [32] designed a temperature-sensitive solid lipid microparticle with a melting point approximating body temperature, which could melt rapidly after being injected into the body. After injecting these microparticles into awake rats via a carotid artery catheter, the CBF was immediately decreased and recovered completely after about $1 \mathrm{~h}$. In the result, the rats were divided into neurologic symptom durations $<24 \mathrm{~h}, 24 \sim 48 \mathrm{~h}$ and $\geq 48 \mathrm{~h}$ groups, and the infarct volume was different in each group. Among these categories, the $<24$ h group without cerebral infarction could be used as TIA model.

Unlike other TIA models, the lipid microparticle model can be prepared without anesthesia, which not only avoids the influence of anesthetic drugs on the experimental results but also allows for the immediate evaluation of the neurologic deficit during TIA and tracking of neurological function recovery in real time. However, this model has excessive variability and its success rate of simulating TIA is low, so the application of this model in TIA-related research is limited.

\section{Platelet aggregation model}

The platelet aggregation model involves the infusion of certain agents (e.g., collagen fibril, ADP) into the carotid artery, which reversibly causes platelet aggregation and platelet thrombosis, eventually inducing transient cerebral ischemia. This model also presents significant variability in the duration and severity of ischemia.

\section{Collagen fibril model}

Fritz et al. [7] infused $0.025 \mathrm{ml} / \mathrm{kg}$ collagen fibrils into the ICA circulation of baboon via an ECA cannula, producing reproducible clinical and EEG features resembling those of TIA patients. It was speculated that TIA might result from the release of chemical substances from atherosclerotic plaques which activated the prostaglandin cascade and led to intravascular platelet aggregation. This model successfully replicates the EEG features of clinical TIA and can be used to explore the mechanism of TIA. However, due to the absence of CBF monitoring, neurological assessment and imaging examination, its effectiveness as a TIA model requires additional investigation.

\section{ADP model}

Fieschi et al. [33] successfully developed a rabbit TIA model by infusing ADP into the carotid artery. They observed platelet thrombosis in the cerebral circulation, reduced CBF, and a significant decrease in systemic blood pressure during
ADP infusion. However, upon cessation of the infusion, the platelet thrombi were fragmented and blood pressure was quickly restored. Unlike with collagen fibrils, ADP can not only promote platelet aggregation but also induce systemic hypotension, causing decreased blood flow in the collateral circulation and inadequate compensation for ischemia, thus exacerbating cerebral ischemia and affecting histopathological outcomes. In addition, severe systemic hypotension may limit subsequent studies.

\section{Cerebral blood flow monitoring methods}

Regardless of the method used to develop a TIA model, it is difficult to ensure adequate cerebral ischemia-reperfusion. CBF monitoring can not only objectively evaluate the occlusion or recanalization of cerebral arteries, but also determine the duration of ischemia, which is an essential tool for preparing and validating a TIA model [34]. Furthermore, by monitoring CBF during the establishment of a TIA model, the success of the model can be assessed in a timely manner, and the validity and reliability of the experimental results can be confirmed. Currently, the methods for monitoring CBF include laser Doppler flowmeter (LDF) monitoring, laser speckle contrast imaging (LSCI), magnetic resonance angiography (MRA), iodine-antipyrine autoradiography, and hydrogen clearance. Among them, LDF is the most widely used method. In addition, new devices such as micro-electrocorticography-functional photoacoustic microscopy system ( $\mu$ ECoG-fPAM) and functional ultrasound (fUS) are also used. In practice, one should weigh the costs and benefits based on experimental needs, species, and modeling methods, and try to choose an appropriate, simple and convenient CBF monitoring method (Table 3).

\section{Conclusion}

Animal models can mimic human TIA and are essential tools for studying the pathogenesis, pathology and treatment of TIA. However, the basic research on TIA is limited, and methods are still being developed. According to the definition of TIA, the establishment of a successful and reliable TIA animal model should follow three criteria [20, 35]: (1) objective evidence of cerebral arteries occlusion and reperfusion, (2) no permanent neurological deficit, (3) no acute cerebral infarction. The importance of the first criterion is to confirm the occurrence of transient cerebral ischemia by monitoring CBF and to promptly exclude the animals with inadequate occlusion or inappropriate reperfusion. The necessity of the second and third criterion relies on a neurological function test and MRI examination (both at $24 \mathrm{~h}$ of reperfusion), making animal models more similar 
Table 3 Comparison of cerebral blood flow monitoring methods in TIA models

\begin{tabular}{|c|c|c|c|}
\hline & Theory & Advantages & Disadvantages \\
\hline \multirow[t]{4}{*}{ LDF } & \multirow[t]{4}{*}{ Laser Doppler frequency deviation } & Easy operation & $\begin{array}{l}\text { Limited to the cortical surface measure- } \\
\text { ment* }\end{array}$ \\
\hline & & Low invasiveness & Single point measurement ${ }^{\#}$ \\
\hline & & High sensitivity & Relative measurement value \\
\hline & & $\begin{array}{l}\text { Ability to monitor CBF quickly, continu- } \\
\text { ously, and in real time }\end{array}$ & $\begin{array}{l}\text { Highly susceptible to environment and } \\
\text { activities (e.g., indoor light, surgery } \\
\text { operation, animal breathing) }\end{array}$ \\
\hline \multirow[t]{5}{*}{ LSCI } & \multirow[t]{5}{*}{ Random interference } & Non-contact & $\begin{array}{l}\text { Limited to the cortical surface measure- } \\
\text { ment }\end{array}$ \\
\hline & & Minimally invasive & $\begin{array}{l}\text { Not suitable for monitoring CBF con- } \\
\text { tinuously }\end{array}$ \\
\hline & & Broad measurement range & Relative measurement value \\
\hline & & High spatio-temporal resolution & $\begin{array}{l}\text { Requires thinning the skull for animals } \\
\text { with thick skulls (high technical dif- } \\
\text { ficulty, and not conducive to long-term } \\
\text { measurement) }\end{array}$ \\
\hline & & $\begin{array}{l}\text { Ability to measure multiple microcircula- } \\
\text { tion parameters (e.g., vascular diameter, } \\
\text { vascular density) }\end{array}$ & \\
\hline \multirow[t]{3}{*}{ MRA } & \multirow[t]{3}{*}{ Inflow enhancement effect } & Noninvasive & High requirements on equipment \\
\hline & & Ability to display cerebral vessels clearly & High cost \\
\hline & & $\begin{array}{l}\text { Visual observation of cerebral vascular } \\
\text { occlusion or patency }\end{array}$ & Inability to monitor $\mathrm{CBF}$ in real time \\
\hline \multirow[t]{3}{*}{ Hydrogen clearance } & \multirow[t]{3}{*}{ Tracer removal theory } & Quantitative measurement & High invasiveness \\
\hline & & High reliability & Unable to monitor CBF continuously \\
\hline & & Low requirements on equipment & \\
\hline \multirow[t]{3}{*}{$\mu$ ECoG-fPAM [27] } & \multirow[t]{3}{*}{$\begin{array}{l}\text { Electrophysiological function and } \\
\text { microvascular resolution }\end{array}$} & $\begin{array}{l}\text { Ability to monitor blood flow dynamics } \\
\text { of deep cerebral vessels* }\end{array}$ & Requires complex equipment \\
\hline & & High spatio-temporal resolution & Requires a high level of operational skill \\
\hline & & $\begin{array}{l}\text { Visual observation of cerebral vascular } \\
\text { morphological changes }\end{array}$ & \\
\hline \multirow[t]{5}{*}{ fUS [38] } & \multirow[t]{5}{*}{ Pulse Doppler technology } & $\begin{array}{l}\text { Ability to monitor CBV of deep cerebral } \\
\text { vessels* }\end{array}$ & Relative measurement value \\
\hline & & Broad measurement range ${ }^{\&}$ & Unavoidable measurement error \\
\hline & & $\begin{array}{l}\text { High spatio-temporal resolution (100 } \mu \mathrm{m} \\
\text { and } 400 \mathrm{~ms} \text {, respectively) }\end{array}$ & $\begin{array}{l}\text { Partial loss of blood flow data caused by } \\
\text { the removal of blood vessels with slow } \\
\text { flow rates }\end{array}$ \\
\hline & & $\begin{array}{l}\text { Suitable for real-time monitoring of } \mathrm{CBF} \\
\text { indifferent brain regions }\end{array}$ & \\
\hline & & Requires no anesthesia & \\
\hline
\end{tabular}

$L D F$ laser Doppler flowmeter, $C B F$ cerebral blood flow, $L S C I$ laser speckle contrast imaging, $M R A$ magnetic resonance angiography, $\mu E C o G$ IPAM micro-electrocorticography-functional photoacoustic microscopy system, $f U S$ functional ultrasound, $C B V$ cerebral blood volume

*The measurement depth of LDF, $\mu$ ECoG-fPAM and fUS is $1 \mathrm{~mm}, 3 \mathrm{~mm}$ and $8 \mathrm{~mm}$, respectively

\#the measurement range of LDF is only $1 \mathrm{~mm}^{3}$

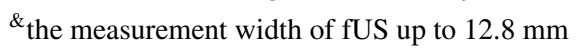

to clinical TIA, and these are also the essential differences between TIA and ischemic stroke models. In summary, the various modeling methods described in this review have unique advantages and disadvantages and should be selected according to specific experimental objectives. In the future, researchers should further optimize these methods based on the above standards to develop an optimal TIA model with minimal invasiveness, good reproducibility, accessible methods, and high translational potential.

Funding This study was supported by the National Natural Science Foundation of China (Grant No. 81873750) and the Hubei Provincial Natural Science Foundation of China (Grant No. 2018CFB115). 


\section{Compliance with ethical standards}

Conflict of interest The authors declare that they have no conflict of interest.

Ethical approval This article does not contain any studies with human participants or animals performed by the authors.

Informed consent For this type of study, formal consent is not required.

Open Access This article is licensed under a Creative Commons Attribution 4.0 International License, which permits use, sharing, adaptation, distribution and reproduction in any medium or format, as long as you give appropriate credit to the original author(s) and the source, provide a link to the Creative Commons licence, and indicate if changes were made. The images or other third party material in this article are included in the article's Creative Commons licence, unless indicated otherwise in a credit line to the material. If material is not included in the article's Creative Commons licence and your intended use is not permitted by statutory regulation or exceeds the permitted use, you will need to obtain permission directly from the copyright holder. To view a copy of this licence, visit http://creativecommons.org/licenses/by/4.0/.

\section{References}

1. Easton JD, Saver JL, Albers GW, Alberts MJ, Chaturvedi S, Feldmann E, Hatsukami TS, Higashida RT, Johnston SC, Kidwell CS, Lutsep HL, Miller E, Sacco RL (2009) Definition and evaluation of transient ischemic attack: a scientific statement for healthcare professionals from the American Heart Association/American Stroke Association Stroke Council; Council on Cardiovascular Surgery and Anesthesia; Council on Cardiovascular Radiology and Intervention; Council on Cardiovascular Nursing; and the interdisciplinary council on peripheral vascular disease. The American Academy of Neurology affirms the value of this statement as an educational tool for neurologists. Stroke 40(6):22762293. https://doi.org/10.1161/strokeaha.108.192218

2. Rothwell PM, Warlow CP (2005) Timing of TIAs preceding stroke: time window for prevention is very short. Neurology 64(5):817-820. https://doi.org/10.1212/01.wnl.0000152985 .32732.ee

3. Sivakumar L, Camicioli R, Butcher K (2014) Factors associated with cognitive decline in transient ischemic attack patients. Can J Neurol Sci 41(3):303-313. https://doi.org/10.1017/s031716710 0017248

4. van Rooij FG, Schaapsmeerders P, Maaijwee NA, van Duijnhoven DA, de Leeuw FE, Kessels RP, van Dijk EJ (2014) Persistent cognitive impairment after transient ischemic attack. Stroke 45(8):2270-2274. https://doi.org/10.1161/strokeaha.114.005205

5. Bejot Y, Daubail B, Giroud M (2016) Epidemiology of stroke and transient ischemic attacks: Current knowledge and perspectives. Revue neurologique 172(1):59-68. https://doi.org/10.1016/j.neuro 1.2015.07.013

6. Wang Y, Zhao X, Jiang Y, Li H, Wang L, Johnston SC, Liu L, Wong KS, Wang C, Pan Y, Jing J, Xu J, Meng X, Zhang M, Li Y, Zhou Y, Zhao W, Wang Y (2015) Prevalence, knowledge, and treatment of transient ischemic attacks in China. Neurology 84(23):2354-2361. https://doi.org/10.1212/wnl.0000000000 001665

7. Fritz VU, Levien LJ (1989) Pathogenesis of transient ischemic attacks and stroke in baboons. Stroke 20(3):386-389. https://doi. org/10.1161/01.str.20.3.386
8. Zhang P, Huang Z, Yan HQ, Su LL, Gui YK, Lv HX, Zhu B, Li T (2014) Improvement of the suture-occluded method in rat models of focal cerebral ischemia-reperfusion. Exp Ther Med 7(3):657-662. https://doi.org/10.3892/etm.2014.1483

9. Traystman RJ (2003) Animal models of focal and global cerebral ischemia. ILAR J 44(2):85-95. https://doi.org/10.1093/ ilar.44.2.85

10. Ponten U, Ratcheson RA, Salford LG, Siesjo BK (1973) Optimal freezing conditions for cerebral metabolites in rats. J Neurochem 21(5):1127-1138. https://doi.org/10.1111/j.1471-4159.1973.tb075 67. $\mathrm{x}$

11. Nishijima Y, Niizuma K, Fujimura M, Akamatsu Y, Shimizu H, Tominaga T (2015) Consistent delayed unilateral neuronal death after modified transient focal cerebral ischemia in mice that mimics neuronal injury after transient global cerebral ischemia. J Neurosurg 123(1):243-253. https://doi.org/10.3171/2014.9.jns14778

12. Kraft P, Gob E, Schuhmann MK, Gobel K, Deppermann C, Thielmann I, Herrmann AM, Lorenz K, Brede M, Stoll G, Meuth SG, Nieswandt B, Pfeilschifter W, Kleinschnitz C (2013) FTY720 ameliorates acute ischemic stroke in mice by reducing thrombo-inflammation but not by direct neuroprotection. Stroke 44(11):3202-3210. https://doi.org/10.1161/strokeaha.113.00288

13. Spetzler RF, Selman WR, Weinstein P, Townsend J, Mehdorn M, Telles D, Crumrine RC, Macko R (1980) Chronic reversible cerebral ischemia: evaluation of a new baboon model. Neurosurgery 7(3):257-261. https://doi.org/10.1227/00006123-19800 9000-00009

14. Liu R, Yang SH (2013) Window of opportunity: estrogen as a treatment for ischemic stroke. Brain Res 1514:83-90. https://doi. org/10.1016/j.brainres.2013.01.023

15. Inagaki T, Etgen AM (2013) Neuroprotective action of acute estrogens: animal models of brain ischemia and clinical implications. Steroids 78(6):597-606. https://doi.org/10.1016/j.stero ids.2012.12.015

16. Buga AM, Balseanu A, Popa-Wagner A, Mogoanta L (2009) Strategies to improve post-stroke behavioral recovery in aged subjects. Rom J Morphol Embryol 50(4):559-582

17. Liu S, Zhen G, Meloni BP, Campbell K, Winn HR (2009) Rodent stroke model guidelines for preclinical stroke trials (1st edition). J Exp Stroke Trans Med 2(2):2-27. https://doi. org/10.6030/1939-067x-2.2.2

18. Fan C, Zhang L, He Z, Shao P, Ding L, Wang G, Niu W, Jia J (2017) Reduced severity of outcome of recurrent ipsilateral transient cerebral ischemia compared with contralateral transient cerebral ischemia in rats. J Stroke Cerebrovasc Dis Off J Natl Stroke Assoc 26(12):2915-2925. https://doi.org/10.1016/j.jstro kecerebrovasdis.2017.07.035

19. Tang YH, Vital S, Russell J, Seifert H, Senchenkova E, Granger DN (2014) Transient ischemia elicits a sustained enhancement of thrombus development in the cerebral microvasculature: effects of anti-thrombotic therapy. Exp Neurol 261:417-423. https://doi. org/10.1016/j.expneurol.2014.07.004

20. Durukan Tolvanen A, Tatlisumak E, Pedrono E, Abo-Ramadan U, Tatlisumak T (2017) TIA model is attainable in Wistar rats by intraluminal occlusion of the MCA for $10 \mathrm{~min}$ or shorter. Brain Res 1663:166-173. https://doi.org/10.1016/j.brainres.2017.03.010

21. Ejaz S, Emmrich JV, Sawiak SJ, Williamson DJ, Baron JC (2015) Cortical selective neuronal loss, impaired behavior, and normal magnetic resonance imaging in a new rat model of true transient ischemic attacks. Stroke 46(4):1084-1092. https://doi. org/10.1161/strokeaha.114.007581

22. Arsava EM, Gurer G, Gursoy-Ozdemir Y, Karatas H, Dalkara T (2009) A new model of transient focal cerebral ischemia for inducing selective neuronal necrosis. Brain Res Bull 78(4-5):226-231. https://doi.org/10.1016/j.brainresbull.2008.11.005 
23. Quenault A, Martinez de Lizarrondo S, Etard O, Gauberti M, Orset C, Haelewyn B, Segal HC, Rothwell PM, Vivien D, Touze E, Ali C (2017) Molecular magnetic resonance imaging discloses endothelial activation after transient ischaemic attack. Brain J Neurol 140(1):146-157. https://doi.org/10.1093/brain/aww260

24. Knapp L, Gellert L, Heredi J, Kocsis K, Olah G, Fuzik J, Kis Z, Vecsei L, Toldi J, Farkas T (2014) A simple novel technique to induce short-lasting local brain ischaemia in the rat. Neuropathol Appl Neurobiol 40(5):603-609. https://doi.org/10.1111/ nan.12069

25. Faught E, Mitchem HL, Conger KA, Garcia JH, Halsey JH Jr (1988) Patterns of EEG frequency content during experimental transient ischaemia in subhuman primates. Neurol Res 10(3):184192. https://doi.org/10.1080/01616412.1988.11739839

26. Watson BD, Dietrich WD, Busto R, Wachtel MS, Ginsberg MD (1985) Induction of reproducible brain infarction by photochemically initiated thrombosis. Ann Neurol 17(5):497-504. https://doi. org/10.1002/ana.410170513

27. Liu YH, Liao LD, Tan SSH, Kwon KY, Ling JM, Bandla A, Shih YI, Tan ETW, Li W, Ng WH, Lai HY, Chen YY, Thakor NV (2015) Assessment of neurovascular dynamics during transient ischemic attack by the novel integration of micro-electrocorticography electrode array with functional photoacoustic microscopy. Neurobiol Dis 82:455-465. https://doi.org/10.1016/j. nbd.2015.06.019

28. Saggu R (2013) Characterisation of endothelin-1-induced intrastriatal lesions within the juvenile and adult rat brain using MRI and 31P MRS. Trans Stroke Res 4(3):351-367. https://doi. org/10.1007/s12975-013-0258-1

29. Horie N, Maag AL, Hamilton SA, Shichinohe H, Bliss TM, Steinberg GK (2008) Mouse model of focal cerebral ischemia using endothelin-1. J Neurosci Methods 173(2):286-290. https://doi. org/10.1016/j.jneumeth.2008.06.013

30. Culp WC, Woods SD, Brown AT, Lowery JD, Hennings LJ, Skinner RD, Borrelli MJ, Roberson PK (2013) Three variations in rabbit angiographic stroke models. J Neurosci Methods 212(2):322328. https://doi.org/10.1016/j.jneumeth.2012.10.017

31. Jannin V, Musakhanian J, Marchaud D (2008) Approaches for the development of solid and semi-solid lipid-based formulations. Adv Drug Deliv Rev 60(6):734-746. https://doi.org/10.1016/j. addr.2007.09.006
32. Tsai MJ, Kuo YM, Tsai YH (2014) Transient ischemic attack induced by melted solid lipid microparticles protects rat brains from permanent focal ischemia. Neuroscience 275:136-145. https ://doi.org/10.1016/j.neuroscience.2014.06.014

33. Fieschi C, Battistini N, Volante F, Zanette E, Weber G, Passero S (1975) Animal model of TIA: an experimental study with intracarotid ADP infusion in rabbits. Stroke 6(6):617-621. https://doi. org/10.1161/01.str.6.6.617

34. Hungerhuber E, Zausinger S, Westermaier T, Plesnila N, SchmidElsaesser R (2006) Simultaneous bilateral laser Doppler fluxmetry and electrophysiological recording during middle cerebral artery occlusion in rats. J Neurosci Methods 154(1-2):109-115. https:// doi.org/10.1016/j.jneumeth.2005.12.004

35. Pedrono E, Durukan A, Strbian D, Marinkovic I, Shekhar S, Pitkonen M, Abo-Ramadan U, Tatlisumak T (2010) An optimized mouse model for transient ischemic attack. J Neuropathol Exp Neurol 69(2):188-195. https://doi.org/10.1097/NEN.0b013e3181 $\operatorname{cd} 331 \mathrm{c}$

36. Berthet C, Lei H, Gruetter R, Hirt L (2011) Early predictive biomarkers for lesion after transient cerebral ischemia. Stroke 42(3):799-805. https://doi.org/10.1161/strokeaha.110.603647

37. Tang YH, Vital S, Russell J, Seifert H, Granger DN (2015) Interleukin-6 mediates enhanced thrombus development in cerebral arterioles following a brief period of focal brain ischemia. Exp Neurol 271:351-357. https://doi.org/10.1016/j.expne urol.2015.06.004

38. Brunner C, Isabel C, Martin A, Dussaux C, Savoye A, Emmrich J, Montaldo G, Mas JL, Baron JC, Urban A (2017) Mapping the dynamics of brain perfusion using functional ultrasound in a rat model of transient middle cerebral artery occlusion. J Cereb Blood Flow Metab Off J Int Soc Cereb Blood Flow Metab 37(1):263276. https://doi.org/10.1177/0271678x15622466

Publisher's Note Springer Nature remains neutral with regard to jurisdictional claims in published maps and institutional affiliations. 